\title{
Effect of herb-drug interactions of Bacopa monnieri Linn. (Brahmi) formulation on the pharmacokinetics of amitriptyline in rats
}

\author{
Fowad Khurshid1 *, Jeyabalan Govindasamy², Habibullah Khalilullah², Mohammed Shivli Nomani², \\ Mudassar Shahid ${ }^{3}$, Md Ruhal Ain ${ }^{4}$, Mohammad Sultan Alsultan ${ }^{5}$

\begin{abstract}
${ }^{1}$ Department of Pharmaceutical Sciences, SunRise University, Alwar, Rajasthan, India, ${ }^{2}$ Department of Pharmaceutical Chemistry, Alwar Pharmacy College, Alwar, Rajasthan, India, ${ }^{3}$ Molecular Virology Laboratory, Department of Biotechnology, Jamia Millia Islamia, Jamia Nagar, New Delhi, India, ${ }^{4}$ School of Pharmacy, OPJS University, Rawatsar Kunjla, Rajgarh, Churu-Rajasthan, India, ${ }^{5}$ Department of Clinical Pharmacy, College of Pharmacy, King Saud University, Riyadh, Saudi Arabia
\end{abstract}

\begin{abstract}
Interactions between herbs and drugs may increase or decrease the pharmacological or toxicological effects of either component. Experimental data on the pharmacokinetic interactions between herbal products and drugs are limited. This study attempted to investigate the effect of Bacopa monnieri Linn. (Brahmi) formulation on the pharmacokinetics of amitriptyline in rats. In this study, rats were randomly divided into two groups $(\mathrm{n}=6 \mathrm{each})$ which were served as a control (amitriptyline alone) and treatment group (amitriptyline with $B$. monnieri), respectively. Rats in the treatment group received $B$. monnieri $(31 \mathrm{mg} / \mathrm{kg} /$ day) whereas the control group received normal saline by oral gavage for seven days before a single intragastric administration of $25 \mathrm{mg} / \mathrm{kg}$ amitriptyline. Plasma concentrations of amitriptyline were measured up to $24 \mathrm{~h}$ after its administration by a developed and validated high-performance liquid chromatography method. Pretreatment with B. monnieri produced a significant increase in the maximum plasma concentration $\left(\mathrm{C}_{\max }\right)$, area under the curve $\left(\mathrm{AUC}_{0-\mathrm{t}}\right)$ and elimination half-life $\left(\mathrm{t}_{1 / 2}\right)$ of amitriptyline by $16.8 \%, 26.5 \%$, and $15.5 \%$, respectively, compared to amitriptyline alone. Moreover, oral clearance and volume of distribution $\left(\mathrm{V}_{\mathrm{ss}}\right.$ ) were decreased by $26.2 \%$ and $15.5 \%$ respectively. This study concluded that B.monnieri significantly enhanced the oral bioavailability of amitriptyline in rats.
\end{abstract}

Keywords: Herbal drug interaction. Bacopa monnieri/effects. Amitriptyline/pharmacokinetics. CYP450. Bioavailability.

\section{INTRODUCTION}

Amitriptyline, a tricyclic compound, has been widely used globally for decades in the treatment of mental illnesses, especially depression. It still serves as one of the most commonly used antidepressants. (Leucht, Huhn, Leucht, 2012). Although the mode of action of amitriptyline is not evident, it is speculated to act by inhibiting the reuptake of serotonin-norepinephrine at the adrenergic nerve endings, thus disrupting the functions of these chemicals (Tatsumi et al., 1997; Amin Bano, 2014). Amitriptyline is completely but slowly absorbed from the gastrointestinal tract after its oral uptake such that the peak plasma concentrations are achieved within 4 to

\footnotetext{
*Correspondence: F. Khurshid. Department of Pharmaceutical Sciences, SunRise University, Alwar-301030, Rajasthan, India. Tel no.: +91-9955881101. E-mail: fowad.khurshid@gmail.com
}

$8 \mathrm{~h}$ of its administration. It has a systemic bioavailability ranging from 33 to $62 \%$ and is subjected to extensive hepatic pre-systemic elimination (Schulz et al., 1983). Within the liver, the drug is primarily metabolized by the action of cytochrome P450 enzymes, namely, CYP2D6, CYP3A4, and CYP2C19 (Rudorfer, Potter, 1999). The significant adverse effects associated with therapeutic concentrations of amitriptyline are manifested in terms of a moderate therapeutic index; an overdose of it may prove to be dangerous.

Bacopa monnieri, a perennial herb, belongs to the family, Scrophulariaceae and is commonly known as Brahmi in the Ayurvedic system of medicine. It has been widely employed as a brain stimulator, antidepressant, and memory enhancer (Stough et al., 2001). Various research studies, performed using the standardized extracts of $B$. monnieri, have demonstrated the herb to facilitate the processes of acquisition, retention, and retrieval of learned 
tasks. A study that evaluated the antidepressant potential of B. monnieri reported it exhibit a significant antidepressant activity in the most commonly used behavior paradigms in animal models of depression. These included forced swim test and learned helplessness test (Sairam et al., 2002). Another study that employed different convulsive models in albino rats to investigate the anticonvulsant activity of an alcoholic extract of $B$. monnieri reported the presence of a broad spectrum of anticonvulsant profile of the extract in chemical, electrical, and hypoxic convulsions (Kaushik et al., 2009). Moreover, a clinical trial conducted to assess the effects of administration of B. monnieri (300 mg/day) over a period of 12 weeks on memory performance reported the ability of the herb to significantly improve the memory acquisition and retention in individuals over the age of 55 years (Morgan, Stevens, 2010). Another study that analyzed the effects of a standardized B. monnieri (300 mg/day) on cognitive performance, anxiety, and depression in the elderly individuals concluded it to be a plant with a potential to safely enhance the cognitive performance in aging (Calabrese et al., 2008). This hypothesis was also favored by the studies conducted in rodents where $B$. monnieri provided protection against age-related oxidative stress and some inflammatory conditions (Williams et al., 2014). It is also known to enhance the lifespan during stress conditions (Phulara et al., 2015). The above-mentioned findings have been strengthened by several clinical studies (Stough et al., 2001; Roodenrys, 2002; Calabrese et al., 2008) that ascribed the observed antidepressant effects to its phytochemical constituents, known as bacoside. Bacoside is a mixture of four triglycosidic saponins, namely, bacoside A3, bacopaside II, bacopaside X, and bacopasaponin C (Singh et al., 1988; Dhawan, Singh, 1996; Russo, Borrelli, 2005).

B. monnieri has an extensive market both in India and outside. The neuropharmacological properties of $B$. monnieri (Russo, Borrelli, 2005; Calabrese et al., 2008) considerably increase the chances of chronic or recurrent usage of the herb and its associated products by patients with mental illnesses. The prescription of therapeutic drugs to these patients significantly contributes to herb-drug interactions at the physiological levels. These interactions, in turn, may increase or decrease the pharmacological or toxicological effects of either component (Hu et al., 2005). Inhibition or induction of hepatic and intestinal drug-metabolizing enzymes, particularly cytochrome P450 (CYP) and transporters (e.g., p-glycoprotein) act as the trigger for the interactions (Zhang et al., 2010a; Wanwimolruk, Prachayasittikul, 2014a; Wanwimolruk, Phopin, Prachayasittikul et al., 2014b). However, there exists a paucity of literature on the pharmacokinetic interactions between herbal products and drugs. The present study attempted to investigate the effects of a commercial formulation of B. monnieri (Brahmi) on the pharmacokinetics of amitriptyline using rodents as the model system. An extensive review of the literature revealed the presence of several analytical methods, based on high-performance liquid chromatography (HPLC), for the estimation of amitriptyline and some of its metabolites in biological samples (Ghahramani, Lennard, 1996; Aymard et al., 1997; Farag et al., 2013). However, the major drawbacks of these procedures are complexity, time constraint, and limited sensitivity, leading to the requirement of a rapid, specific, and sensitive analytical method. The present study aimed to develop a highly sensitive reversed-phase high-performance liquid chromatography (RP-HPLC-UV) method, followed by its validation for the quantification of amitriptyline in rat plasma.

\section{MATERIAL AND METHODS}

\section{Material}

Amitriptyline and imipramine, as internal standards (ISs), were purchased from Sigma-Aldrich (Germany). High-performance liquid chromatography (HPLC) grade LiChrosolv methanol and LiChrosolv acetonitrile were from Merck (Darmstadt, Germany). Chemicals of highest available commercial purity were utilized. The commercial formulation of B. monnieri (Himalaya Drug Company, Bangalore, India) was procured from the local market. The HPLC-grade solvents were used for HPLC determinations. Milli-Q plus water (Millipore, Bedford, MA, United States) was used for all preparations. All other chemicals were of analytical grade.

\section{Animals and study design}

The study was conducted in accordance with current legislation on animal experiments as per Institutional Animal Ethical Committee (CPCSEA Approval no. 962/ $\mathrm{PO} / \mathrm{Re} / \mathrm{S} / 06 / \mathrm{CPCSEA})$. Twelve male Wistar albino rats, weighing 225 to $250 \mathrm{~g}$ were provided by the animal house, Alwar Pharmacy College, Alwar, Rajasthan. The rats were housed under standard animal conditions with alternate 12 $\mathrm{h}$ of light and dark cycles in an environment maintained at a constant temperature prior to the study. Water was supplied ad libitum. Rats were randomly divided into two groups ( $n=6$ each); one served as the control (amitriptyline alone), and the other group served as the treatment group 
(amitriptyline with B. monnieri). A randomized parallel design study was employed to study the pharmacokinetics of amitriptyline. Rats in the control group were provided normal saline orally $(10 \mathrm{~mL} / \mathrm{kg})$ for 7 consecutive days followed by administration of amitriptyline $(25 \mathrm{mg} / \mathrm{kg}$ bw p.o.) on day $8,1 \mathrm{~h}$ after administration of normal saline. Amitriptyline was administered as an aqueous solution in $0.5 \%(\mathrm{w} / \mathrm{v})$ sodium carboxy-methyl cellulose (CMC) at a dose of $25 \mathrm{mg} / \mathrm{kg}$ bw p.o. Rats in the treatment group were administered $B$. monnieri extract in $0.5 \% \mathrm{CMC}$ at a dose of $31 \mathrm{mg} / \mathrm{kg} /$ day, p.o. in saline water (Singh et al., 2013) for 7 consecutive days. The rats were made to fast for at least $12 \mathrm{~h}$ (overnight) with free access to water before the day of the experiment. On the morning of day 8 , the last dose of $B$. monnieri was administered to the fasting rats. One hour after the administration of the last dose of $B$. monnieri, amitriptyline aqueous solution in $0.5 \%(\mathrm{w} / \mathrm{v})$ CMC (25 mg/kg p.o.) was administered to these rats. The drug was administered via gastric gavage throughout the study.

\section{Blood collection}

A total of $1 \mathrm{~mL}$ of blood samples were collected into heparinized vacutainer tubes from the retroorbital plexus of each rat using capillary tubes before and after the administration of amitriptyline at $0,1,2,4,6,8,12$, and $24 \mathrm{~h}$. The blood samples were immediately centrifuged at $2,500 \times \mathrm{g}$ for $10 \mathrm{~min}$ to separate the plasma that was stored at $-80{ }^{\circ} \mathrm{C}$ until analysis. To replace the fluid loss, equal volumes of normal saline were injected through the cannula in all experiments. The same sampling scheme was followed for rats in the treatment group to determine the plasma concentrations of amitriptyline and evaluate the effect of $B$. monnieri on amitriptyline disposition in rats.

\section{Amitriptyline assay by HPLC Method}

\section{Instrumentations and chromatographic conditions}

The high-performance liquid chromatography (Waters, 1525 Binary HPLC pump) employed was equipped with the Waters-2489 UV-visible detector and Waters-2707 Autosampler and operated by Breeze 2 service pack A (SPA) software, Waters Corporation. The chromatographic identification was conducted at ambient temperature. The mobile phase consisted of a $\mathrm{v} / \mathrm{v}$ ratio of acetonitrile and potassium dihydrogen phosphate buffer $\left(\mathrm{KH}_{2} \mathrm{PO}_{4} 38: 62\right)$, which was delivered at the isocratic condition with a flow rate of $1 \mathrm{~mL} / \mathrm{min}$. EC 150/4.6-NUCLEODUR Sphinx RP, $5 \mu \mathrm{m}$ MACHERY-
NAGEL column was used to elute amitriptyline at a wavelength $\left(\lambda_{\max }\right)$ of $254 \mathrm{~nm}$. Different combinations of solvent systems of acetonitrile, buffer $\left(\mathrm{KH}_{2} \mathrm{PO}_{4}\right)$ : acetonitrile, and formic acid: water, and methanol: water: acetonitrile were tried to determine the optimum conditions for the separation and standardization of amitriptyline. The mobile phase consisted of acetonitrile and $70 \mathrm{mM} \mathrm{KH} \mathrm{PO}_{4}$ buffer. Its $\mathrm{pH}$ was adjusted to 4.5 by $85 \%$ orthophosphoric acid in a ratio of $38: 62(\mathrm{v} / \mathrm{v})$. The selection of mobile phase was based on its ability to provide high resolution for amitriptyline with minimal tailing.

\section{Sample preparation}

The samples for analysis were prepared by the protein precipitation method. Plasma samples stored at around $-80^{\circ} \mathrm{C}$ were thawed at room temperature and vortexed for $30 \mathrm{~s}$ to ensure homogeneity. The internal standard ( $8 \mu \mathrm{L}, 100 \mu \mathrm{g} / \mathrm{mL})$ was added to $200 \mu \mathrm{L}$ of plasma sample, and $592 \mu \mathrm{L}$ of acetonitrile was added to precipitate the protein from the sample. The samples were mixed gently for 1.5 min followed by centrifugation at $12,000 \mathrm{rpm}$ for $10 \mathrm{~min}$. After centrifugation, $700 \mu \mathrm{L}$ of clear supernatant was transferred into HPLC vials. Finally, $25 \mu \mathrm{L}$ of each sample was subjected to HPLCUV analysis.

\section{Calibration and control samples}

The linearity of an analytical method refers to its ability to furnish test results that are directly proportional to the concentration of an analyte in the samples within a given range. In other words, linearity is the relationship between the concentration of analyte and assay measurement (ICH, 1996). We used correlation coefficient $\left(R^{2}\right)$ obtained from the linear regression to demonstrate the linearity of the relationship between the peak area ratio and the concentration. The experiment was performed in triplicates with the concentration of analyte ranging from 0.125 to $50.0 \mu \mathrm{g} / \mathrm{mL}$. The relative standard deviations were calculated for all the calibration curve slopes. The observed straight-line equation, $\mathrm{y}=0.0343 \times-0.0026\left(R^{2}=0.9994\right)$ was used for the calculation of plasma concentrations of amitriptyline.

\section{Validation and stability of HPLC method}

The guidelines of the international conference on harmonization were employed to validate the HPLC method in terms of linearity, specificity, sensitivity, 
precision, and accuracy (ICH, 1996). The robustness of the method was evaluated by intentionally introducing minor modifications in the mobile phase volume ratios. These included mobile phase having different compositions of acetonitrile- $70 \mathrm{mM} \mathrm{KH}_{2} \mathrm{PO}_{4}(6038: 62 \pm 5 \mathrm{~mL})$, alteration of the $\mathrm{pH}$ of buffer $(4.5 \pm 0.2)$, and slight changes in the isocratic flow rate $(1.0 \pm 0.2 \mathrm{~mL} / \mathrm{min})$ of the mobile phase. All the validation parameters were studied in triplicate $(n=3)$ at a concentration of $20 \mu \mathrm{g} / \mathrm{mL}$. The stability of amitriptyline in plasma at 4 and $20^{\circ} \mathrm{C}$ and after freezethaw cycles was determined.

\section{Pharmacokinetic analysis}

We utilized the non-compartmental analysis to determine the pharmacokinetic parameters of amitriptyline after oral administration. The maximum observed plasma concentration $\left(\mathrm{C}_{\max }\right)$ and the time to reach this concentration $\left(\mathrm{T}_{\max }\right)$ following oral administration were calculated from the observed data. The volume of distribution at steady state $\left(\mathrm{V}_{\mathrm{ss}}\right)$ was calculated as $\left(\mathrm{AUMC}_{0 \text {-inf }} / \mathrm{AUC}_{0 \text {-inf }}\right) * \mathrm{CL}$ and total body clearance $(\mathrm{CL})$ as dose $/ \mathrm{AUC}_{0 \text {-inf }}$. The area under the plasma concentration versus time curve $\left(\mathrm{AUC}_{0-\mathrm{t}}\right)$ was calculated by the trapezoidal rule with extrapolation to infinity. The linear regression analysis of the terminal portion of the log concentration-time data was utilized to calculate the apparent terminal elimination rate constant $\left(K_{\mathrm{el}}\right.$ or $\left.\lambda_{\mathrm{z}}\right)$ of amitriptyline. Amitriptyline apparent terminal elimination half-life $\left(\mathrm{t}_{1 / 2}\right)$ was calculated as $(\ln 2) / \lambda \mathrm{z}$, where $\lambda z$ is the elimination rate constant. Pharmacokinetic analysis was performed using the program, PKSolver for Microsoft Excel (Zhang et al., 2010b).

\section{Statistical data analysis}

All statistical data were expressed as the mean \pm standard deviation (SD). Student's $t$-test on logtransformed data was utilized for assessing the differences in the pharmacokinetic parameters of amitriptyline with and without B. monnieri. Data were considered statistically significant at a $p<0.05$. All calculations were performed using GraphPad Prism, version 3.00 for Windows (San Diego, CA, United States).

\section{Herbal medicine and dose calculation}

The recommended adult dose of $B$. monnieri extract containing $20 \%$ of total bacopasides was 300 to $400 \mathrm{mg}$ daily. A dose equivalent to human dose was used as the animal dose of these herbs and was calculated using the following equation.
Human equivalent dose $(\mathrm{mg} / \mathrm{kg})=$ Animal dose $(\mathrm{mg} / \mathrm{kg}) \times \frac{\text { Animal } \mathrm{Km}}{\text { Human } \mathrm{Km}}$

The human dose was selected from authentic herbal textbook resources (Reagan-Shaw, Nihal, Ahmad, 2008). The rat dose was found to be $31 \mathrm{mg} / \mathrm{kg} / \mathrm{day}$ (Singh et al., 2013).

\section{RESULTS AND DISCUSSION}

\section{HPLC method development and validation for amitriptyline assay}

The mobile phase of HPLC column was selected on the basis of previously used and described methods available for amitriptyline (Shen et al., 2010; Farag et al., 2013). The $\mathrm{KH}_{2} \mathrm{PO}_{4}$ buffer was checked at different concentrations $(0.02,0.05$, and $0.07 \mathrm{M})$ for determining its efficient working concentration. At lower concentrations, amitriptyline and IS did not result in the same retention time. At a buffer concentration of 0.07 $\mathrm{M}$, the analytes were found to be well separated from plasma and hence it was chosen as the optimal buffer concentration. A range of buffer $\mathrm{pH}(3.0-7.0)$ was assayed to optimize the chromatographic separation. Optimal peak separation for amitriptyline and IS was produced using a $\mathrm{pH}$ value ranging between 3.0 and 7.0. However, when the spiked matrix samples were analyzed, the peaks from some of the plasma impurities matched with that of IS. A pH value of 4.5 was found to be optimal for the complete separation of amitriptyline and imipramine (IS); at this $\mathrm{pH}$ value, peaks were resolved well. The final mobile phase consisted of acetonitrile- $\mathrm{KH}_{2} \mathrm{PO}_{4}(0.07 \mathrm{M})$, $\mathrm{pH} 4.5$ with $1.0 \mathrm{~mL} / \mathrm{min}$ flow rate. This condition was found to be outstanding in terms of sensitivity and peak separation. The wavelengths checked in the present study were 230, 240, and $254 \mathrm{~nm}$ (Olsen, Sullivan, 1995). The wavelength of $254 \mathrm{~nm}$ was found to be optimal in terms of sensitivity for all the analytes; it also avoided the occurrence of numerous matrix impurities and exogenous substances.

\section{Selectivity and specificity}

The selectivity of any analytical method refers to the ability of the method to assess the analyte unequivocally in the presence of endogenous matrix compounds (i.e., plasma and proteins in this method). The chromatograms of plasma samples by using HPLC method are depicted in Figure 1. The symmetrical peaks were observed for amitriptyline with a retention 
time of $6.15 \mathrm{~min}$. There was no interference with the amitriptyline peak, and the overall chromatographic run time was $10 \mathrm{~min}$. HPLC chromatograms of blank plasma (Figure 1A), plasma spiked with imipramine as IS $25 \mathrm{ng} /$ $\mathrm{mL}$ (Figure 1B), plasma sample spiked with amitriptyline $(20 \mu \mathrm{g} / \mathrm{mL})$ with retention times of $6.15 \mathrm{~min}$. Retention time of the IS was 4.52 min (Figure 1C). The plasma samples obtained from rat, administered with $25 \mathrm{mg} / \mathrm{kg}$ p.o. dose of amitriptyline (Figure 1D), were compared to show the selectivity of the adopted HPLC method. The retention times of amitriptyline and imipramine were approximately 6.15 and $4.52 \mathrm{~min}$, respectively. The designed HPLC method was found to be considerably selective, reflected by the absence of the appearance of any other interfering peaks around the retention times due to endogenous matrix substances or metabolite effects during quantification of amitriptyline and imipramine (IS) in plasma samples.
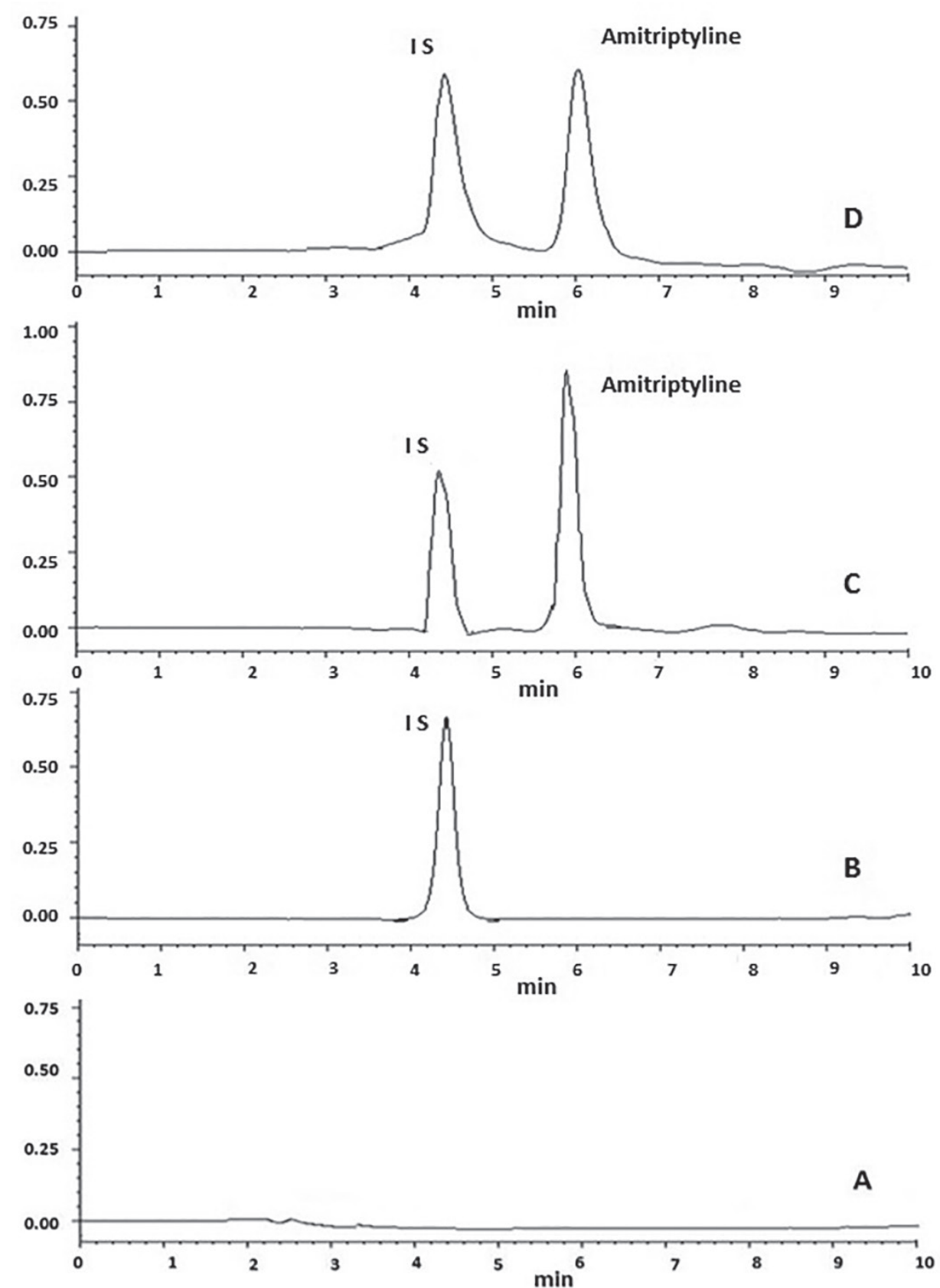

FIGURE 1 - HPLC chromatogram of blank plasma (A), plasma spiked with imipramine as internal standard (I.S) (B), plasma sample spiked with amitriptyline $\left(20 \mu \mathrm{g} / \mathrm{mL}\right.$ concentration) $\left(R_{\mathrm{t}} 6.15 \mathrm{~min}\right)$ and $\mathrm{IS}\left(R_{\mathrm{t}} 4.5 \mathrm{~min}\right)(\mathrm{C})$, plasma samples obtained from rat, administered with $25 \mathrm{mg} / \mathrm{kg}$, p.o. dose of amitriptyline (D). 


\section{Precision and accuracy of developed HPLC method}

An evaluation of the concentrations of three levels, namely, LLOQ, MQC, and ULOQ indicated the relative standard deviation (\% RSD) values to be satisfactory. The calculated percentage recovery of the MQC level was found to be $100.14 \pm 0.15 \%$. The recovery values obtained from the analysis of different known concentrations by the developed HPLC method ranged from 98.31 to 99.02 , indicating the method to be highly accurate. The percentage recovery determined for the lowest concentration (LLOQ) and MQC were 98.31 \pm 0.85 and $99.23 \pm 0.15 \%$, respectively, and that of the highest concentration(ULOQ) was $99.02 \pm 0.54 \%$ during the inter-day analysis of the samples. All the results are listed in Table I. The reproducibility and reliability of the method was evident by low values of \% RSD for LLOQ, MQC, and ULOQ.

\section{Sensitivity, Limit of Detection (LOD), and Limit of Quantification (LOQ)}

The lower limit of quantitation (LLOQ) was defined as the concentration of the lowest non-zero calibration standard, which met the acceptance criteria for accuracy and precision. The signal-to-noise ratios of 3.3:1 and 10:1 were considered as LOD and LOQ, respectively, and were found to be 0.04334 and $0.13134 \mu \mathrm{g} / \mathrm{mL}$, respectively.

\section{Stability}

Studies on the stability of the drug were performed to ensure reproducibility and reliability of the method. The amitriptyline stock solutions and its working stock solutions were stable at $4{ }^{\circ} \mathrm{C}$ for 3 months. The stability of the analyte in rat plasma was investigated under different storage conditions. It was found to be stable under the following conditions: at $10{ }^{\circ} \mathrm{C}$ for $24 \mathrm{~h}$ post-extraction, after three freeze and thaw cycles (from -20 to $25^{\circ} \mathrm{C}$ ) and at $-80{ }^{\circ} \mathrm{C}$ for 90 days. The results of stability studies are summarized in Table II.

\section{Recovery and matrix effects}

The vortexing and ultracentrifugation were used for the extraction of the analyte and the IS. The percentage extraction recoveries of amitriptyline were found to be $65.25,76.75$, and $74.28 \%$ in the low (LQC), medium (MQC), and high (HQC) concentration quality control samples $(n=6)$, respectively. The percentage extraction recovery of the IS was $61.65 \%$. We did not detect any apparent matrix effect in the determination of amitriptyline by this method of analysis. The values for the three quality control samples, i.e., LQC, MQC, and HQC were reported to be $100.4,100.13$, and $100.29 \%$, respectively.

\section{Carryover test}

The HPLC chromatograms obtained by using the presently developed method of a blank sample (IS without amitriptyline) were analyzed following six consecutive analyses of ULOQ samples. The analysis revealed no obvious carryover.

\section{Pharmacokinetic analysis}

The pharmacokinetic parameters of amitriptyline are summarized in Table III. The mean plasma concentrations versus time profiles of amitriptyline after oral administration with and without $B$. monnieri were characterized in rats and are presented in Figure 2. The peak plasma concentration $\left(\mathrm{C}_{\max }\right)$ was significantly $(p<0.05)$ increased by $16.8 \%(2.86 \pm 0.11$ to $3.34 \pm 0.06 \mu \mathrm{g} / \mathrm{mL}$ ) in the presence of $B$. monnieri. Similarly, the area under the plasma concentration-time curve, $\mathrm{AUC}_{0-24}$ and $\mathrm{AUC}_{0 \text {-inf }}$ significantly increased by $26.5 \%(29.34 \pm 0.90$ to $37.12 \pm 0.62 \mu \mathrm{g} \cdot \mathrm{h} / \mathrm{mL})$ and $36.7 \%$

TABLE I - Inter- and intra-day precision and recovery as accuracy of quality control samples (mean $\pm \mathrm{SD}, n=3$ )

\begin{tabular}{lccccccc}
\hline \multirow{2}{*}{ Parameters } & \multirow{2}{*}{ Values } & \multicolumn{3}{c}{ Inter-day $(\boldsymbol{\mu g} / \mathbf{m L})$} & \multicolumn{3}{c}{ Intra-day $(\boldsymbol{\mu g} / \mathbf{m L})$} \\
\cline { 3 - 8 } & & LLOQ (10) & MQC (30) & ULOQ (50) & LLOQ (10) & MQC (30) & ULOQ (50) \\
\hline \multirow{2}{*}{ Precision } & Mean \pm SD & $9.73 \pm 0.03$ & $28.96 \pm 0.14$ & $48.92 \pm 0.98$ & $9.65 \pm 0.02$ & $29.02 \pm 0.16$ & $49.06 \pm 0.97$ \\
& \%RSD & 1.65 & 2.98 & 1.85 & 1.52 & 0.85 & 1.45 \\
\hline \multirow{2}{*}{ Recovery } & Mean \pm SD & $9.95 \pm 0.08$ & $29.96 \pm 0.04$ & $49.82 \pm 0.32$ & $10.34 \pm 0.02$ & $30.02 \pm 0.15$ & $50.51 \pm 0.25$ \\
\hline & \% Recovery & 98.31 & 99.23 & 99.02 & 100.49 & 100.13 & 100.29 \\
& \%RSD & 0.85 & 0.15 & 0.54 & 0.99 & 0.51 & 0.185 \\
\hline
\end{tabular}


TABLE II - Results of stability study of QC samples at different conditions (mean $\pm \mathrm{SD}, n=3$ )

\begin{tabular}{lcc}
\hline Stability test & $\begin{array}{c}\text { Initial concentration } \pm \mathbf{S D} \\
(\boldsymbol{\mu g} / \mathbf{m L})\end{array}$ & $\begin{array}{c}\text { Measured concentration } \pm \text { SD } \\
(\boldsymbol{\mu g} / \mathbf{m L})\end{array}$ \\
\hline Stock solution $\left(4^{\circ} \mathrm{C}\right.$ for 3 months $)$ & 250.00 & $249.06 \pm 1.26$ \\
Working solution $\left(4{ }^{\circ} \mathrm{C}\right.$ for 3 months $)$ & $30.00(\mathrm{HQC}$ sample $)$ & $29.56 \pm 0.56$ \\
\hline & ${ }^{\mathrm{a}} 58.83 \pm 0.12$ & $58.60 \pm 0.49$ \\
Post-extraction $\left(10^{\circ} \mathrm{C}\right.$ for $\left.24 \mathrm{~h}\right)$ & ${ }^{\mathrm{b}} 29.25 \pm 0.05$ & $28.81 \pm 0.45$ \\
& ${ }^{\mathrm{c}} 9.15 \pm 0.09$ & $9.04 \pm 0.16$ \\
\hline & ${ }^{\mathrm{a}} 59.01 \pm 1.08$ & $58.83 \pm 0.42$ \\
Freeze-thaw (from $-20{ }^{\circ} \mathrm{C}$ to $25^{\circ} \mathrm{C}, 3$ cycles $)$ & ${ }^{\mathrm{b}} 29.25 \pm 1.12$ & $29.11 \pm 0.15$ \\
& ${ }^{\mathrm{c}} 9.88 \pm 1.01$ & $9.33 \pm 0.43$ \\
\hline & ${ }^{\mathrm{a}} 58.54 \pm 0.98$ & $58.82 \pm 0.27$ \\
Long term $\left(-80{ }^{\circ} \mathrm{C}\right.$ for 90 days $)$ & ${ }^{\mathrm{b}} 29.42 \pm 0.78$ & $29.04 \pm 0.22$ \\
& ${ }^{\mathrm{c}} 9.02 \pm 0.29$ & $8.94 \pm 0.089$ \\
\hline
\end{tabular}

Note: ${ }^{a}$ values of ULOQ $(60 \mu \mathrm{g} / \mathrm{mL})$ and ${ }^{\mathrm{b}}$ values of MQC $(30 \mu \mathrm{g} / \mathrm{mL})$ samples and ${ }^{\mathrm{c}}$ values of LLOQ $(10 \mu \mathrm{g} / \mathrm{mL})$

TABLE III - Pharmacokinetic parameters of amitriptyline control (alone) and co-administered with B.monnieri (mean $\pm \mathrm{SD}, \mathrm{n}=6)$

\begin{tabular}{|c|c|c|}
\hline Pharmacokinetic parameters & $\begin{array}{r}\text { Amitriptyline only } \\
(\text { mean } \pm \text { SD, } n=6)\end{array}$ & $\begin{array}{l}\text { Amitriptyline with B.monnieri } \\
\quad(\text { mean } \pm \mathrm{SD}, n=6)\end{array}$ \\
\hline${ }^{1} \mathrm{C}_{\max }(\mu \mathrm{g} / \mathrm{mL})$ & $2.86 \pm 0.11$ & $3.34 \pm 0.06^{*}$ \\
\hline${ }^{2} \mathrm{~T}_{\max }(\mathrm{h})$ & $4.0 \pm 0.00$ & $4.0 \pm 0.00$ \\
\hline${ }^{3} \mathrm{~K}_{\mathrm{el}}\left(\mathrm{h}^{-1}\right)$ & $0.07 \pm 0.0079$ & $0.062 \pm 0.0021^{*}$ \\
\hline${ }^{4} \mathrm{AUC}_{0-24}(\mu \mathrm{g} \cdot \mathrm{h} / \mathrm{mL})$ & $29.34 \pm 0.90$ & $37.12 \pm 0.62 *$ \\
\hline${ }^{5} \mathrm{AUC}_{0 \text {-inf }}(\mu \mathrm{g} \cdot \mathrm{h} / \mathrm{mL})$ & $38.38 \pm 1.23$ & $52.46 \pm 1.73^{*}$ \\
\hline${ }^{6} \mathrm{AUMC}_{0 \text {-inf }}(\mu \mathrm{g} \cdot \mathrm{h} / \mathrm{mL})$ & $617.77 \pm 26.04$ & $984.13 \pm 63.33^{*}$ \\
\hline${ }^{7} \mathrm{t}_{1 / 2}(\mathrm{~h})$ & $9.63 \pm 0.21$ & $11.13 \pm 0.39 *$ \\
\hline${ }^{8} \mathrm{~V}_{\mathrm{ss}}(\mathrm{L} / \mathrm{Kg})$ & $9.05 \pm 0.26$ & $7.65 \pm 0.07^{*}$ \\
\hline${ }^{9} \mathrm{CL}(\mathrm{mL} / \mathrm{h})$ & $0.65 \pm 0.02$ & $0.48 \pm 0.02 *$ \\
\hline${ }^{10} \mathrm{MRT}(\mathrm{h})$ & $16.09 \pm 0.27$ & $18.74 \pm 0.59 *$ \\
\hline
\end{tabular}

*Significant difference from "Amitriptyline alone" group with t-test, ${ }^{*} \mathrm{P} \leq 0.05,{ }^{1}$ maximum blood concentration $\left(\mathbf{C}_{\max }\right),{ }^{2}$ time of peak concentration $\left(\mathbf{T}_{\max }\right),{ }^{3}$ elimination rate constant $\left(\mathbf{k}_{\mathrm{el}}\right),{ }^{4}$ area under the concentration time profile curve until last observation $\left(\mathbf{A U C} \mathbf{C}_{0-24}\right),{ }^{5}$ area under the concentration time profile curve from time 0 to infinity $\left(\mathbf{A} \mathbf{U} \mathbf{C}_{0-\text { inf }}\right),{ }^{6}$ area under the first moment curve concentration time profile curve from time 0 to infinity $\left(\mathbf{A} \mathbf{U} \mathbf{M C}_{0 \text {-inf }}\right),{ }^{7}$ half-life $\left(\mathrm{t}_{1 / 2}\right),{ }^{8}$ Steady-State Volume distribution $\left(\mathbf{V}_{\text {ss }}\right),{ }^{9}$ Total clearance $(\mathbf{C L})$, and ${ }^{10}$ mean residence time (MRT)

$(38.38 \pm 1.23$ to $52.46 \pm 1.73)$, respectively, compared to the control group. However, there was no significant change in the time to reach the peak plasma concentration $\left(\mathrm{T}_{\max }\right)$ of amitriptyline in the presence of B. monnieri. On the other hand, the calculated total oral clearance (CL) decreased by $26.2 \%(0.65 \pm 0.02$ to $0.48 \pm 0.02 \mathrm{~mL} / \mathrm{h}$; $p<0.05)$, while the estimated apparent oral volume of distribution $\left(\mathrm{V}_{\mathrm{ss}}\right)$ at steady state decreased by about $15.5 \%(9.05 \pm 0.26$ to $7.65 \pm 0.07 \mathrm{~L} / \mathrm{kg} ; p<0.05)$. Also, an increase of elimination half-life $\left(\mathrm{t}_{1 / 2}\right)$ from $9.63 \pm 0.21$ to
$11.12 \pm 0.39 \mathrm{~h}$, which is about $15.5 \%$ as compared to the control group, was reported.

Our study revealed the potential of $B$. monnieri to significantly alter the oral pharmacokinetic profile of amitriptyline compared with the control. This is attributed to the considerable enhancement in the oral bioavailability of amitriptyline in rats. Various studies indicate the importance of herbal drugs to alter the expression of drugmetabolizing enzymes and membrane transporters after administration. Cytochrome P450 (CYPs) are the primary 


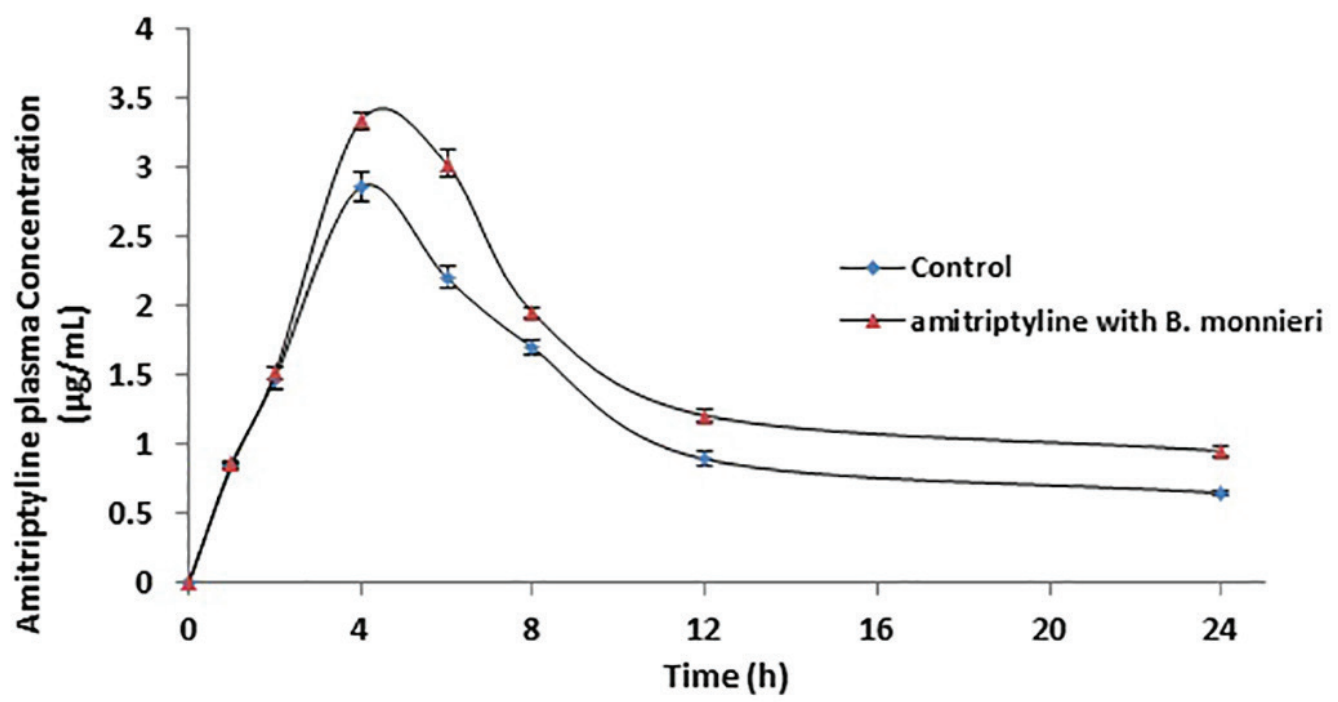

FIGURE 2 - Plasma concentration-time curve of amitriptyline $(25 \mathrm{mg} / \mathrm{kg}, \mathrm{p} . \mathrm{o})$ administered with and without B.monnieri $(31 \mathrm{mg} / \mathrm{kg} /$ day, p.o) in rats (each data is mean $\pm \mathrm{SD}, n=6)$

enzymes in the liver involved in the hepatic metabolism of most drugs. These comprise CYP1A2, CYP3A4, CYP2C9, CYP2C19, CYP2D6, and CYP2E1 (Badyal, Dadhich, 2001). Amitriptyline, after oral administration, is readily absorbed by the gastrointestinal tract, followed by its metabolism, majorly on its first pass through the liver. CYP2D6-, CYP3A4-, and CYP2C19-mediated $\mathrm{N}$-demethylation into nortriptyline constitute the main pathway for its metabolism (Rudorfer, Potter, 1999). Recently, a study conducted to evaluate the effects of a standardized extract of $B$. monnieri on the expression and activity of hepatic and intestinal cytochrome P450 3A and P-glycoprotein (Pgp) in rats revealed that administration of $B$. monnieri for 7 days modulated the expression of CYP3A and Pgp. Administration of B. monnieri led to a reduced expression of CYP3A and concomitant decrease in the CYP3A-dependent testosterone hydroxylase catalytic activity in liver and intestine (Singh et al., 2013). Another study reported similar findings that $B$. monnieri moderately inhibited CYP2C19, CYP2C9, CYP1A2, and CYP3A4 but weakly inhibited CYP2D6 (Ramasamy, Kiew, Chung, 2014). These findings indicated toward the possible potential of $B$. monnieri to contribute to herb-drug interactions when orally co-administered with drugs metabolized by CYP1A2, CYP3A4, CYP2C9, and CYP2C19. Based on this hypothesis, the plasma levels of drug administered concomitantly could be elevated by inhibition of drug-metabolizing enzymes to prolong the pharmacological effects of the drug, thereby increasing the incidence of drug-induced toxicity (Hu et al., 2005). The enhanced bioavailability of amitriptyline observed in the current study might result from the inhibition of the metabolizing enzymes, CYP3A4 and CYP2C19, in the intestinal mucosa or liver by $B$. monnieri. Another reason for the inhibition of the CYP enzymes by $B$. monnieri could be the presence of other constituents in the extract, such as free aglycones, such as jujubogenin (Kawai et al., 1974) and pseudojujubogenin (Kawai, Shibata, 1978), which are more lipophilic. The better lipophilic property of free aglycones enhances their binding to the CYP isoforms through hydrogen bonding, thereby resulting in stronger inhibitory effects (Ramasamy, Kiew, Chung, 2014). The increase in $C_{\max }$ and area under curve (AUC) and decrease in oral clearance may lead to increase in the total bioavailability of amitriptyline, leading to toxic effects. Hence, concomitant administration of B. monnieri preparations with drugs that are primarily cleared through CYP2C19-, CYP2C9-, CYP1A2-, and CYP3A4-mediated metabolism should be administered to the patients with increased vigilance

\section{CONCLUSION}

The findings of the present study suggest that the medicinal herb, B. monnieri exhibit significant potential to alter pharmacokinetics of amitriptyline in rats. The herb-drug interaction was reflected by the $B$. monnierimediated increased intestinal absorption and reduced first-pass metabolism of amitriptyline in the intestine and liver through inhibition of CYP2C and CYP3A enzymes. The results obtained in the present study indicate toward exercising caution while administering a combination of 
B. monnieri and amitriptyline. Consequently, concomitant use of $B$. monnieri and amitriptyline warrants close monitoring for possible drug interactions. Further confirmation of these results in humans would assist in evaluating the clinical consequences of such interactions.

\section{CONFLICT OF INTEREST}

The authors declare that there is no conflict of interest regarding the publication of this paper.

\section{REFERENCES}

Amin F, Bano B. Effect of amitriptyline an antidepressant drug on structural and functional properties of brain cystatin. J Mol Genet Med 2014;8(2):1000103.

Aymard G, Livi P, Pham YT, Diquet B. Sensitive and rapid method for the simultaneous quantification of five antidepressants with their respective metabolites in plasma using high-performance liquid chromatography with diodearray detection. J Chromatogr B Biomed Sci Appl 1997;700(12):183-189.

Badyal DK, Dadhich AP. Cytochrome P450 and drug interactions. Indian J Pharmacol 2001;33:248-259.

Calabrese C, Gregory WL, Leo M, Kraemer D, Bone K, Oken B. Effects of a standardized bacopa monnieri extract on cognitive performance, anxiety, and depression in the elderly: a randomized, double-blind, placebo-controlled trial. J Altern Complement Med 2008;14(6):707-713.

Dhawan BN, Singh HK. Pharmacological studies on Bacopa monniera, an Ayurvedic nootropic agent. Eur Neuropsychopharmacol 1996;6(Supp 3):144.

Farag RS, Darwish MZ, Fathy WM, Hammad HA. New HPLC method to detect amitriptyline in the blood of rats on combination treatment. Int J Chem Analyt Sci 2013;4(2):120124.

Ghahramani P, Lennard MS. Quantitative analysis of amitriptyline and nortriptyline in human plasma and liver microsomal preparations by high-performance liquid chromatography. J Chromatogr B Biomed Appl 1996;685(2):307-313.

Hu Z, Yang X, Ho PC, Chan SY, Heng PW, Chan E, Duan W, Koh HL, Zhou S. Herb-drug interactions: a literature review. Drugs 2005;65(9):1239-1282.
International Conference on Harmonisation. ICH Harmonised tripartite guideline-guidance for industry: Q2B validation of analytical procedures: methodology. Geneva: ICH;1996. 17 p.

Kaushik D, Tripathi A, Tripathi R, Ganachari M, Khan SA. Anticonvulsant activity of Bacopa monniera in rodents. Braz J Pharm Sci 2009;45(4):643-649.

Kawai K-I, Akiyama T, Ogihara Y, Shibata S. A new sapogenin in the saponins of Zizyphus jujuba, Hovenia dulcis and Bacopa monniera. Phytochemistry 1974;13(12):2829--2832.

Kawai K-I, Shibata S. Pseudojujubogenin, a new sapogenin from Bacopa monniera. Phytochemistry 1978;17(2):287--289.

Leucht C, Huhn M, Leucht S. Amitriptyline versus placebo for major depressive disorder. Cochrane Database Syst Rev 2012;12:CD009138. issue number is missing

Morgan A, Stevens J. Does Bacopa monnieri improve memory performance in older persons? Results of a randomized, placebo-controlled, double-blind trial. J Altern Complement Med 2010;16(7):753-759.

Olsen BA, Sullivan GR. Chemometric categorization of octadecylsilyl bonded-phase silica columns using test mixtures and confirmation of results with pharmaceutical compound separations. J Chromatogr A 1995;692(1-2):147-159.

Phulara SC, Shukla V, Tiwari S, Pandey R. Bacopa monnieri promotes longevity in Caenorhabditis elegans under stress conditions. Pharmacogn Mag 2015;11(42):410-416.

Priyanka HP, Singh RV, Mishra M, ThyagaRajan S. Diverse age-related effects of Bacopa monnieri and donepezil in vitro on cytokine production, antioxidant enzyme activities, and intracellular targets in splenocytes of F344 male rats. Int Immunopharmacol 2013;15(2):260-274.

Ramasamy S, Kiew L, Chung L. Inhibition of human cytochrome p450 enzymes by bacopa monnieri standardized extract and constituents. Molecules 2014;19(2):2588-2601.

Reagan-Shaw S, Nihal M, Ahmad N. Dose translation from animal to human studies revisited. FASEB J 2008;22(3):659661.

Roodenrys S. Chronic effects of brahmi (Bacopa monnieri) on human memory. Neuropsychopharmacology 2002;27(2):279281. 
Rudorfer MV, Potter WZ. Metabolism of tricyclic antidepressants. Cell Mol Neurobiol 1999;19(3):373-409.

Russo A, Borrelli F. Bacopa monniera, a reputed nootropic plant: an overview. Phytomedicine 2005;12(4):305-317.

Sairam K, Dorababu M, Goel RK, Bhattacharya SK. Antidepressant activity of standardized extract of Bacopa monniera in experimental models of depression in rats. Phytomedicine 2002;9(3):207-211.

Schulz P, Turner-Tamiyasu K, Smith G, Giacomini KM, Blaschke TF. Amitriptyline disposition in young and elderly normal men. Clin Pharmacol Ther 1983;33(3):360-366.

Shen Y, Zhu RH, Li HD, Liu YW, Xu P. Validated LC-MS (ESI) assay for the simultaneous determination of amitriptyline and its metabolite nortriptyline in rat plasma: application to a pharmacokinetic comparison. J Pharm Biomed Anal 2010;53(3):735-739.

Singh HK, Rastogi RP, Srimal RC, Dhawan BN. Effect of bacosides A and $\mathrm{B}$ on avoidance responses in rats. Phytother Res 1988;2(2):70-75.

Singh R, Panduri J, Kumar D, Kumar D, Chandsana H, Ramakrishna R, Bhatta RS. Evaluation of memory enhancing clinically available standardized extract of Bacopa monniera on P-glycoprotein and cytochrome P450 3A in Sprague-Dawley rats. PLoS One 2013a;8(8):e72517.
Stough C, Lloyd J, Clarke J, Downey LA, Hutchison CW, Rodgers T, Nathan PJ. The chronic effects of an extract of Bacopa monniera (Brahmi) on cognitive function in healthy human subjects. Psychopharmacology (Berl) 2001;156(4):481484 .

Tatsumi M, Groshan K, Blakely RD, Richelson E. Pharmacological profile of antidepressants and related compounds at human monoamine transporters. Eur J Pharmacol 1997;340(2-3):249-258.

Wanwimolruk S, Phopin K, Prachayasittikul V. Cytochrome P450 enzyme mediated herbal drug interactions (Part 2). Excli J 2014b;13:869-896.

Wanwimolruk S, Prachayasittikul V. Cytochrome P450 enzyme mediated herbal drug interactions (Part 1). Excli J 2014a;13:347391.

Williams R, Munch G, Gyengesi E, Bennett L. Bacopa monnieri (L.) exerts anti-inflammatory effects on cells of the innate immune system in vitro. Food Funct 2014;5(3):517-520.

Zhang L, Reynolds KS, Zhao P, Huang S-M. Drug interactions evaluation: An integrated part of risk assessment of therapeutics. Toxicol Appl Pharmacol 2010a;243(2):134-145.

Zhang Y, Huo M, Zhou J, Xie S. PKSolver: An add-in program for pharmacokinetic and pharmacodynamic data analysis in Microsoft Excel. Comput Methods Programs Biomed 2010b;99(3):306-314.

Received for publication on $27^{\text {th }}$ February 2017 Accepted for publication on $26^{\text {th }}$ June 2017 